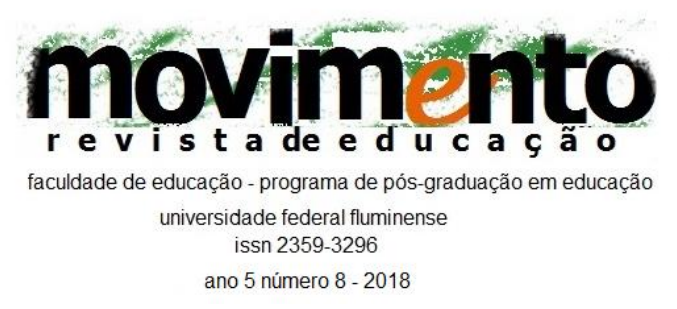

\title{
AVALIAÇÃO DAS ESCOLAS E REGULAÇÃO POLÍTICO- NORMATIVA: uma análise de discursos
}

\author{
Dora Fonseca \\ Universidade de Aveiro, \\ Aveiro, Portugal \\ Jorge Adelino Costa \\ Universidade de Aveiro, \\ Aveiro, Portugal
}

\begin{abstract}
Resumo
Em Portugal, nas últimas décadas, o discurso político-normativo em torno da educação tem sido marcado por uma gramática que alguns autores apelidam de gerencialista. Neste trabalho, procuramos proceder a uma análise sobre esse assunto, tendo por base, por um lado, o normativo legal que enquadra a avaliação das escolas (Lei ํㅜ 31/2002) e, por outro, as construções discursivas da Inspeção da Educação (relatórios de avaliação externa das escolas) e das escolas (relatórios de avaliação interna das escolas).

Palavras-chave: Avaliação das escolas; Regulação transnacional; Políticas educativas.
\end{abstract}

\section{EVALUATION OF SCHOOLS AND POLITICAL AND NORMATIVE REGULATION: an analysis of discourses}

\begin{abstract}
In Portugal, in recent decades, the political and normative discourse around the education has been marked by a grammar that some authors have calledgerencialista. We're looking for, in this work, carry out an analysis on this subject on the basis of, on the one hand, the legal standard that is part of the evaluation of schools (Law 31/2002) and, on the other, the discursive constructions of Education Inspection (external evaluation reports of the schools) and schools (internal evaluation reports of schools). Keywords: School evaluation; Transnational regulation; Educational policies.
\end{abstract}

\section{EVALUACIÓN DE LAS ESCUELAS Y REGULACIÓN POLÍTICA- NORMATIVA: un análisis de discursos}

\footnotetext{
Resumen

En Portugal, en las últimas décadas, el discurso político y normativo en torno a la educación ha estado marcado por una gramática que algunos autores han denominado gerencialista. En el presente trabajo hacemos un análisis sobre este tema, basándose,
} 


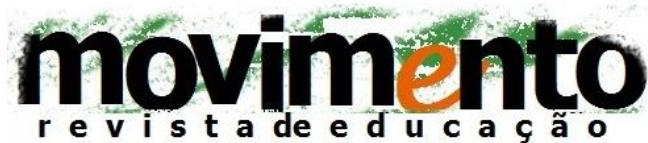 \\ faculdade de educação - programa de pós-graduação em educação universidade federal fluminense \\ issn 2359-3296 \\ ano 5 número 8 - 2018}

por una parte, en la normativa legal que enmarca la evaluación de las escuelas (Ley no 31/2002) y, por otra, las construcciones discursivas de la Inspección de la Educación (informes de evaluación externa de las escuelas) y de las escuelas (informes de evaluación interna de las escuelas).

Palabras clave: Evaluación de las escuelas; Regulación transnacional; Políticas educativas.

\section{Introdução}

Não abandonando alguns propósitos e terminologia de natureza democrática, os normativos legais que têm sido produzidos pelo poder central nestes últimos anos revelam uma faceta gestionária utilizada com uma linguagem bélica ao nível do discurso político na área da educação, como afirmou contudentemente Formosinho \& Machado (2007). São vários os investigadores (SEIXAS, 2001; SÁ, 2002; BARROSO \& VISEU, 2003; LIMA, 2011) que nos alertam para essa forte orientação nas políticas educativas em Portugal, o que, aliás, tem acontecido também em outros países.

Diversos estudos revelam que se regista uma propagação do ideário neoliberal no campo educativo traduzido na expansão das ideias de mercado ou quasemercado educacional. Gradualmente, assistimos a uma mudança discursiva no plano educativo que se traduz em um certo afastamento do discurso democratizante e em uma aproximação ao discurso gestionário. Essa tendência tem sido clara nas produções documentais de várias entidades supranacionais que aconselham e determinam, de maneira mais ou menos explícita, os caminhos que os distintos países, no nosso caso, da União Europeia, "deverão" seguir em matéria educativa.

Neste trabalho, pretendemos revelar essa tendência no contexto português, explorando as questões da avaliação organizacional. De forma mais ou menos generalizada, os processos de avaliação das organizações educativas 


\section{movimento \\ faculdade de educação - programa de pós-graduação em educação universidade federal fluminense \\ issn 2359-3296 \\ ano 5 número 8 - 2018}

implementados assumem objetivos de melhoria de funcionamento das escolas, de transparência dos processos educativos, de prestação de contas à comunidade. Por outro lado, eles também promovem processos de competição entre as escolas com a intenção de favorecer lógicas de eficácia e eficiência educativas.

Através da análise dos discursos produzidos nos relatórios de avaliação das escolas, este artigo procura mostrar que os processos de avaliação não se constituem como efetivos mecanismos de emancipação e de desenvolvimento organizacional, mas como reproduções dos múltiplos discursos político-legais produzidos externamente à escola. Essa situação contribui para a obstaculização do desenvolvimento de processos autonómicos dos atores em âmbito local e para a "manutenção" de um discurso educacional marcado por tendências gestionárias.

Em um primeiro momento, procuramos assinalar o fato de as regulações transnacionais influenciarem as políticas educativas (neste caso, as portuguesas), revelando o abandono progressivo de um discurso democrático, que era dominante no plano das orientações normativo-legais, avançando para novas formas discursivas que combinam discursos de natureza democrática e de gerencialista, com o predomínio deste em relação ao anterior (LIMA, 1994; Lima, 2011). Em seguida, com base nos discursos sobre a avaliação das escolas, pretendemos explorar a ideia de que as construções discursivas produzidas pelos atores em suas localidades revelam essa mesma tendência, podendo ser entendidas como resultado das pressões/regulações externas a que os indivíduos e as organizações se encontram sujeitos. 


\section{movimento \\ faculdade de educação - programa de pós-graduação em educação universidade federal fluminense \\ issn 2359-3296 \\ ano 5 número 8 - 2018}

\section{A educação e as regulações supranacionais}

Como proposto em outros trabalhos (CASTRO, 2011; CASTRO, 2015), as políticas de educação refletem o cruzamento de várias pressões que emergem de centros de decisão transnacional. Para explicitar essas pressões exercidas sobre a administração e a gestão educacionais, importa rever o conceito de regulação, em particular aquele tratado no âmbito das políticas educativas (NETO-MENDES, 2004; BARROSO, 2006; LIMA, 2006; AFONSO, 2006; PINHAL, 2006; AZEVEDO, 2008). Segundo Barroso (2006, p.11-12), falar de regulação no contexto da administração educativa é entender duas dimensões da problemática, ou seja, "descrever dois tipos de fenómenos diferenciados, mas interdependentes. Os modos como são produzidas e aplicadas as regras que orientam a ação dos atores e os modos como esses mesmos atores se apropriam delas e as transformam". Esse pressuposto é central no nosso trabalho: primeiro pretendemos identificar as orientações do discurso político e, posteriormente, perceber como os atores se apropriam e/ou transformam essas mesmas orientações.

É nosso pressuposto que as políticas educacionais estão profundamente marcadas pelas produções e pelas decisões de entidades supranacionais que hoje influenciam claramente as políticas em todos os países (CASTRO, 2011). São vários os organismos desse tipo que contribuem formal ou informalmente para a regulação (transnacional) da educação nos diferentes países (AZEVEDO, 2000; SEIXAS, 2001; TEODORO, 2001; NETO-MENDES, 2004; DIAS, 2004; BARROSO, 2006, NÓVOA, 2009; CASTRO,2011).

Considerando os vários estudos realizados, instituições como o Banco Mundial, o Fundo Monetário Internacional (FMI), a Organização para a Cooperação e o Desenvolvimento Econômico (OCDE), a Organização das Nações Unidas para a Educação, a Ciência e a Cultura (UNESCO), a União Europeia e o Conselho 


\section{movimento \\ faculdade de educação - programa de pós-graduação em educação universidade federal fluminense \\ issn 2359-3296 \\ ano 5 número 8 - 2018}

da Europa, entre outras, têm marcado a direção das políticas educativas nos diferentes países. Na esteira de António Teodoro (2001), dizemos que o gerencialismo global faz deslocar, progressivamente, o poder dos vários Estados-Nação para organizações supranacionais as quais aos poucos assumem o controlo das agendas políticas em educação. Também Pacheco (2011, p. 16) entende que as pressões e as regulações supranacionais acabam por ter um efeito de padronização e de homogeneização da educação:

a mudança transnacional circunscreve-se a modelos institucionais padronizados, enquadrados pelas ideologias da sociedade de informação, do conhecimento e das novas competências e regulados por procedimentos de gestão administrativa.

Tal como entende Pacheco (2011), as questões do currículo e as decisões tomadas nessa matéria são ilustrativas de homogeneização nos diversos países e em diferentes níveis: estruturas e percursos curriculares, seleção e organização de conteúdos e áreas curriculares, valorização de determinadas áreas curriculares em detrimento de outras e formas de avaliação de escolas e alunos (inclusive as formas de regulação e controle externo).

Segundo alguns investigadores, podemos verificar algumas práticas dominantes de tendência mais gestionária e que têm ganhado terreno nos diferentes países no âmbito da gestão e da administração escolar. Referimo-nos ao discurso da descentralização da educação e da autonomia pela via da contratualização e da privatização da escola pública focada na satisfação do cliente, na gestão educativa centrada em lideranças fortes com especial enfoque para lideranças unipessoais e, ainda, da cultura de gestão da qualidade e de uma gestão racionalizadora com prestação de contas à comunidade, em uma lógica de eficácia e eficiência.

Como exemplo, podemos citar a pressão para resultados educativos concretos facilmente identificados e mensuráveis com que cada vez mais nos deparamos. 


\section{movimento \\ faculdade de educação - programa de pós-graduação em educação universidade federal fluminense \\ issn 2359-3296 \\ ano 5 número 8 - 2018}

Em grande medida, tal pressão decorre do espaço supranacional através dos seus discursos das agendas político-educativas. As organizações supranacionais, situadas nos países centrais, "ditam" regras e estabelecem linhas orientadoras, o que leva alguns países, sobretudo os periféricos, à posição de dependência e de subordinação em relação a um centro instituído. As pressões $e$ as regulações supranacionais acabam por determinar 0 "comportamento aconselhável" que as organizações educativas e os seus atores deverão seguir e revelar (CASTRO, 2015). Como aponta Nóvoa (2009, p.29), temos assistido a uma "série de classificações internacionais que não se limitaram a descrever uma situação, mas que constituíram categorias de pensamento, que definiram modalidades de ação".

Em Portugal, os discursos no âmbito das políticas educacionais feito em diferentes canais e através dos normativos legais têm revelado alterações discursivas que remetem para novas categorias de pensamento e que se mostram em sintonia com as tendências globais: o deslocar de um discurso marcadamente de natureza democrática para um gerencialista.

Assim, temos assistido a discursos em torno da necessidade de gerir a educação de uma forma mais racionalizadora com base em princípios de qualidade, de rigor, de transparência e de prestação de contas. Referindo-se às mudanças nas políticas educativas e no que diz respeito concretamente à gestão e administração educacional, Dias (2004, p. 255) explica que temos assistido ao privilegiar de novas posições como "a abertura às regras do mercado, a redefinição das competências entre a administração central e as escolas, a diluição entre as fronteiras dos setores público e privado, a diversificação das formas de prestação de contas e de controlo".

Seixas (2001) entende que a "ideologia tecnocrática constitui a base das ideologias modernas da maioria dos países desenvolvidos, acentuando a 


\section{movimento \\ faculdade de educação - programa de pós-graduação em educação universidade federal fluminense \\ issn 2359-3296 \\ ano 5 número 8 - 2018}

importância da educação para a competitividade económica nacional num mercado cada vez mais global" e que essa situação coloca a política educativa subalternizada às económicas. Estevão (2008) alerta para o facto de a globalização ter

(...) vindo a impor um novo mandato aos diferentes países no sentido de, em nome de vantagens competitivas que podem alcançar e, também, em nome do combate à crise, terem de redefinir os seus sistemas de ensino e de formação nacionais em termos de qualidade, avaliada segundo padrões internacionais.

Portanto, Portugal não se encontra imune às regulações supranacionais que se fazem sentir no campo educativo, traduzidas nas recomendações e nas sugestões resultantes de estudos comparados e na aplicação de instrumentos de avaliação de forma uniformizante e com os mesmos referenciais nos vários países da Europa.

\section{Reconfigurações do papel do Estado}

Em Portugal, a gestão do sistema educativo tem sido marcada pela centralização, pela hierarquização e pela burocratização nos processos. Para além das fortes regulações supranacionais e do seu impacto no desenvolvimento das políticas educativas nacionais, o Estado continua a ter um papel determinante e regulador na/da vida das escolas. Mesmo integrando o discurso da importância de processos autonómicos e descentralizados em educação nos normativos legais, o poder central (Ministério da Educação) continua a exercer fortes regulações sobre as diferentes instâncias de administração educacional, escolas e atores, quer de forma direta, através das diferentes estruturas e dispositivos, ou por meio de normativos legais.

É através desses diferentes dispositivos e da legislação que o Estado continua a controlar as organizações educativas e os seus atores nos processos e 


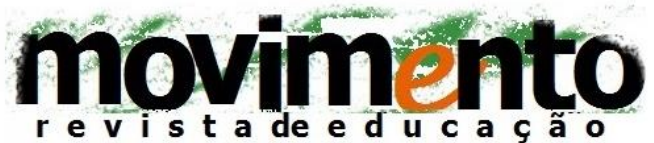 \\ faculdade de educação - programa de pós-graduação em educação universidade federal fluminense \\ issn 2359-3296 \\ ano 5 número 8 - 2018}

também agora nos resultados. Nestes últimos tempos, temos identificado várias formas de controle externo das escolas no domínio da avaliação, dentre as quais destacamos as provas externas e os exames dos alunos nos diferentes níveis educativos e a avaliação externa das escolas.

A verificação e o controle dos resultados educativos tornaram-se aspetos centrais na ação/regulação do Estado em relação às escolas, conferindo-lhe uma nova faceta: a de Estado-avaliador. Seguindo as ideias de Estevão (2008, p. 506), o Estado acaba por entrar "na lógica dominante, a mercantil, "desmonumentalizando-se" e deixando o seu antigo poder imperial, mas assegurando a difusão das ideias da eficiência e eficácia, dando assim o seu contributo para o funcionamento do mercado".

Assim, o Estado não abdica do seu papel de controlador do sistema educativo, mas alia-se à força mercantil, revelando alguma subordinação às regras do mundo económico (CASTRO, 2011). A propósito das regulações exercidas sobre as escolas, Neto-Mendes (2004, p.26) adianta que a profissionalidade docente é construída entre "uma lógica de regulação estatal e uma lógica de regulação de mercado". Os próprios normativos legais (produzidos pelo Ministério da Educação) contribuem para a implementação e para a pressão dessas duas lógicas distintas.

Contudo, não é incomum percecionarmos um discurso ambíguo e contraditório, ainda mais visível se compararmos as intenções políticas (presentes nos preâmbulos dos normativos) com as medidas concretas apresentadas para serem desenvolvidas na realidade educativa. Registamos incongruências discursivas quando comparamos normativos ou outros documentos produzidos pelas diferentes estruturas do Ministério da Educação, ou mesmo quando estudamos a coerência interna de cada documento. 


\section{movimento \\ faculdade de educação - programa de pós-graduação em educação universidade federal fluminense \\ issn 2359-3296 \\ ano 5 número 8 - 2018}

Fontoura (2008, p.20-21), seguindo as palavras de Lima (1999), dá conta da ambiguidade e das contradições dos termos e da sua interseção entre os ideais da democracia e as lógicas gerencialistas. Alerta-nos para o tipo de medidas que são implementadas no terreno e que, na ação, muitas vezes contrariam o discurso em torno dos ideais democráticos. A autora diz-nos que as medidas utilizadas "despojam a «descentralização e a autonomia de sentido político democrático-participativo»" revelando-se, sobretudo, as "suas conceções instrumentais «de tipo gerencial, técnico-implementativo ou desregulador".

Tendo em conta estudos realizados por nós sobre a construção de instrumentos de gestão educacional (projetos de intervenção dos diretores, projetos educativos e cartas educativas), podemos assinalar que o discurso políticonormativo influencia a construção discursiva dos atores em âmbito local (COSTA, 2007; CASTRO, 2011; CASTRO, FIGUEIREDO \& DIOGO, 2015). A relação poder central (Governo e Ministério) - poder local (atores que exercem a sua ação na esfera educativa) continua a ser de natureza hierárquica e verticalista, encontrando-se regulados os processos e os resultados pela via do discurso político-normativo difundido pelos diferentes canais de comunicação entre o Ministério da Educação e as escolas/municípios.

Essa mudança do papel do Estado - que agora assume o papel de avaliador também leva a alterações discursivas que se evidenciam nas produções legislativas. A preocupação exacerbada com a avaliação pela parte do poder central, revelada em muitos dos normativos, anuncia que o Estado passou a atuar como avaliador e como monitorizador do sistema educativo. Para Seixas (2001, p. 220), o discurso do Estado-avaliador, "associado aos discursos da modernidade tecnocrática, é essencialmente um discurso de mercado". 


\section{movimento \\ faculdade de educação - programa de pós-graduação em educação universidade federal fluminense \\ issn 2359-3296 \\ ano 5 número 8 - 2018}

\section{Avaliação das escolas: a centralidade da prestação de contas e da qualidade}

Explorar o conceito de avaliação organizacional não é um assunto que possa ser tratado de forma simplista nem linear, pois estamos perante um conceito com vários significados e que depende do posicionamento teórico a partir do qual nos colocamos. Azevedo (2002, p.7) considera que os conceitos de avaliação "enunciam-se de lugares muito diferentes, orientam-se para finalidades muito diversas e percorrem caminhos metodológicos também muito variados". Para Moreira (2005, p.18), as diferentes dimensões da avaliação educacional perspetivam-se "num quadro político-pedagógico e organizacional de avaliação", conduzindo a fins distintos conforme os próprios interesses dos atores e das organizações. É, portanto, em um quadro político específico que determinadas ações avaliativas têm sido levadas a cabo. Por isso, no entender de vários investigadores portugueses (AFONSO, 2002; LIMA, 2002; AFONSO, 2010), elas revelam uma feição de natureza tecnocrática e positivista de certa forma.

Partindo do princípio de que a avaliação não se constitui como um ato neutro, Moreira (2005, p.19) diz-nos que a "avaliação coloca-se como uma questão eminentemente política, como uma amálgama de valores políticos, técnicocientíficos, atitudinais, éticos e pedagógicos" ou, como adianta ainda a autora citando Dias Sobrinho (1995), que a "avaliação [...] toma partidos, reafirma os valores considerados positivos, denega o que julga negativo, interfere nas relações sociais de trabalho e intervém em todas as dimensões da vida académica e institucional".

Os dispositivos de avaliação que foram implementados na área da educação (do desempenho dos profissionais e das organizações) nestes últimos anos obedecem a referenciais pré-definidos por entidades externas ou muito controlados por elas. Focam-se em resultados e seguem as lógicas da 


\section{movimento \\ faculdade de educação - programa de pós-graduação em educação \\ universidade federal fluminense \\ issn 2359-3296 \\ ano 5 número 8 - 2018}

mensurabilidade. São vários os estudos desenvolvidos em Portugal que têm evidenciado que os processos de avaliação levados a cabo em instituições educativas têm contribuído mais para alimentar as lógicas de mercado educacional (como é o caso de rankings) do que constituído verdadeiros processos de desenvolvimento profissional e organizacional (CASTRO, 2016). Tendo por base o estudo sobre os mecanismos de avaliação externa, Almerindo Afonso alerta para a necessidade de perceber que

(...) a adopção de certos dispositivos de avaliação externa (sobretudo os que são exclusivamente baseados em indicadores quantificáveis e mensuráveis) não contribuirá para a tão propagandeada melhoria da qualidade do ensino, representando antes um retrocesso político e educacional injustificável face sobretudo, aos progressos científicos e epistemológicos que vinham conduzindo a avaliação para perspectivas anti-positivistas mais complexas e plurais (Afonso, 2001, p. 24).

A crescente valorização da accountability baseada em instrumentos de avaliação estandardizados, em âmbito interno ou externo, transforma os processos de avaliação em excelentes instrumentos de controlo. Ainda relativamente à hipervalorização dos resultados educacionais com referência a padrões instituídos, Formosinho e Machado (2007, p.101) afirmam que a "garantia de uma excelência máxima" se apoia no "controlo direto e tanto possível objetivo dos resultados dos alunos tarefa esta que «corresponde à verificação industrial do produto, no que diz respeito à quantidade e qualidade".

Na mesma lógica de controlo e de verificação de produto, a avaliação nas organizações educativas tem ganhado centralidade. Lima (2002, p.26) entende que os processos avaliativos estão enformados pelas perspetivas racionais e instrumentais da avaliação e que a avaliação dominante pertence a "um paradigma positivista da avaliação, baseado no «mito» da medição". Reforçando essa ideia, Afonso (2002, p.31) afirma que a avaliação é "um instrumento de gestão subordinada aos novos valores da produtividade instrucional, da 


\section{movimento \\ faculdade de educação - programa de pós-graduação em educação universidade federal fluminense \\ issn 2359-3296 \\ ano 5 número 8 - 2018}

performatividade e da prestação de contas". Essa necessidade de controlar os processos em função de um resultado previsto a alcançar leva a que os atores desenvolvam as suas práticas de avaliação tendo em conta «novos» referenciais que se situam na esfera gestionária. Daí que se tenham vindo a "introduzir processos «racionais» de gestão, com a formulação explícita de metas, elaboração de planos estratégicos para identificar prioridades de desenvolvimento, avaliação de resultados, «controlo de qualidade»" (BARROSO, 2005, p.97).

A melhoria de resultados - traduzidos de forma mensurável recorrendo à evidência de se atingirem as metas previamente traçadas - torna-se o objetivo central dos processos de avaliação nas organizações educativas. O controlo e a monitorização da ação, tendo como referentes as decisões pré-determinadas, constituem aspetos fundamentais para conferir a excelência da escola.

A qualidade organizacional é associada à verificação da eficácia e da eficiência da organização traduzida em resultados que se «medem» através de indicadores e evidências. A medição e a hierarquização das escolas (rankings) a partir dos resultados produzidos - a "escola contábil" nas palavras de Lima (2011) - torna-se essencial para produzir e para mostrar uma determinada imagem da escola que possa competir por um melhor lugar nos rankings educacionais.

Preocupando-se com a avaliação interna das escolas e, sobretudo, colocando em causa o rigor e a precisão de que se reveste esse processo, Rufino (2007, p.33) desperta-nos para o perigo da manipulação dos dados e dos resultados pela via da utilização de determinados instrumentos de avaliação que modelam os fatos. O autor diz-nos que a "matriz de indicadores de qualidade de um instrumento de avaliação exprime valores subjacentes a objetivos políticos, reveladores do sentido pretendido da modelação do objeto onde são aplicados". 


\section{movimento \\ faculdade de educação - programa de pós-graduação em educação universidade federal fluminense \\ issn 2359-3296 \\ ano 5 número 8 - 2018}

A propósito dos processos de autoavaliação nas escolas, Simões (2007, p.399) alega que existem novos referenciais associados a conceitos como eficácia, eficiência e qualidade e, tal como entende Lima (2011), são termos que estão "naturalizados e associados a dimensões positivas" (LIMA, 2011, p.39) e que não deixam de ser "vazios" de sentido em certa medida.

Também Pacheco (2011, p.17) entende que os efeitos económicos e políticos estão bem presentes nos processos de educação e que são visíveis nas "orientações de diversos organismos" através de "conceitos-chave, tais como «qualidade», «prestação de contas», "aprendizagem ao longo da vida», «economia do conhecimento», "competência», «excelência»". Os docentes e as escolas confrontam-se com a necessidade de produzir instrumentos, de considerar indicadores e taxas, de determinar metas e de revelar evidências para desenvolverem processos de monitorização do(s) processo(s) educativo(s). Essas questões passaram a ser centrais nos processos de avaliação nas organizações educativas, ou seja, o importante é estar em conformidade com aquilo que é expectável. Esses processos avaliativos externo acabam por determinar como serão desenvolvidas as formas de autoavaliação das organizações educativas. Tal como Afonso (2010) refere,

(...) a centralidade da avaliação externa amplia necessariamente a secundarização da autoavaliação, o que, mesmo assim, não explica completamente o facto de esta última ser a componente de avaliação institucional menos consolidada e valorizada.

Assim, entendemos que os próprios atores acabam por facilitar ou mesmo intensificar uma certa subordinação a centros instituídos e, ao mesmo tempo, alimentar as lógicas de mercado educacional que se têm afirmado. Nesse sentido, parece ter faltado a valorização de uma perspetiva mais crítica e interpretativa e de um verdadeiro diálogo entre o olhar interno e o externo, dada 


\section{movimento \\ faculdade de educação - programa de pós-graduação em educação universidade federal fluminense \\ issn 2359-3296 \\ ano 5 número 8 - 2018}

a afirmação dominante da visão tecnocrática nesses processos. Segundo Afonso,

perante a emergência dos novos mecanismos de governança, será plausível esperar, em Portugal e noutros contextos, que os sistemas de avaliação acabem sobretudo por justificar a expansão (e eventual tecno-burocratização) de estruturas especializadas para a sua gestão e implementação (...) radicalmente afastados dos interesses (e das vozes) dos actores educativos e das especificidades dos contextos locais e institucionais (AFONSO, 2010, p.352).

Em Portugal, a imagem da escola pública em falência e à deriva (sem qualquer prestação de contas do seu trabalho e sem qualidade) tem sido divulgada para apresentar e legitimar o desenvolvimento de outras possibilidades no campo da administração educacional que, hipoteticamente, ofereceriam mais qualidade.

No entanto, o próprio conceito de qualidade pode ser ambíguo e diverso conforme as lógicas em que se inscreve a sua aplicação. Gazïel, Warnet \& Cantón Mayo (2000, p- 67) enumeram três conceções de qualidade que se entrecruzam, a saber: as qualidades centradas nos processos, nos resultados da organização e no cliente e no contexto.

Segundo os autores, identifica-se um modelo organizacional relacionado com cada uma das conceções de qualidade referidas. Há modelos que privilegiam o carácter qualitativo, interpretativo e simbólico e que assentam nas duas primeiras conceções de qualidade. Há também os modelos organizacionais racional e burocrático que, por outro lado, erguem-se a partir da conceção de qualidade centrada no cliente e no contexto.

Esses autores referem ainda duas perspetivas filosóficas que podem influenciar o conceito de qualidade: a igualitarista e a individualista. A primeira salienta aspetos como a equidade e a justiça social, enquanto a outra enfatiza o 


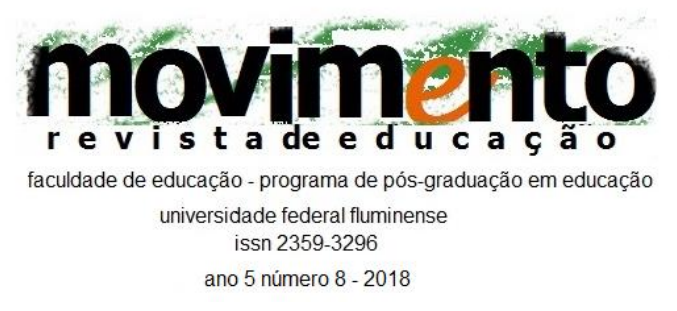

individualismo e a competitividade (GAZÏEL, WARNET \&CANTÓN MAYO,2000, pp.68-69).

Percebemos que o conceito ou conceitos de qualidade dependerão sempre dos quadros de referência em que se situam. Ora, é nesse contexto do discurso da qualidade educacional em uma lógica gestionária que se desenvolvem ações de natureza avaliativa (assente na perspetiva individualista e centrada no cliente e no contexto), as quais não são mais do que mecanismos de controlo dos profissionais e das organizações educativas no sentido de promover a "qualidade" definida através de indicadores padronizados a uma escala global.

\section{Discursos presentes nos documentos de avaliação das escolas em investigação exploratória}

O presente estudo de natureza exploratória situa-se no contexto educativo português e, em um primeiro momento, integra a análise do discurso políticonormativo presente na lei que orienta os processos de avaliação das escolas em Portugal (Lei $n .-0$ 31/2002, de 20 de dezembro), bem como em outros documentos produzidos pela Inspeção da Educação, nomeadamente o Quadro de referência para a avaliação externa das escolas. Posteriormente, analisaremos dez relatórios de avaliação externa de escolas produzidos por equipas da responsabilidade da Inspeção da Educação e outros dez relatórios de avaliação interna de escolas desenvolvidos pelas equipas de avaliação destas. Todos os relatórios de avaliação foram recolhidos na internet aleatoriamente.

A análise feita ao normativo legal e ao documento orientador da Inspeção incidiu nas questões estruturais e de conteúdo e na contagem de conceitos presentes que consideramos pertencerem a uma gramática gerencialista ou a uma gramática democrática (socorremo-nos, nesse caso, ao quadro teórico que 


\section{movimento \\ faculdade de educação - programa de pós-graduação em educação universidade federal fluminense \\ issn 2359-3296 \\ ano 5 número 8 - 2018}

desenvolvemos anteriormente sobre o tema: Castro, 2011). Posteriormente, analisamos os relatórios de avaliação das escolas, tendo em conta as seguintes categorias: i) a estrutura; ii) orientações gerais dos processos, iii) domínios e campos de análise; iv) referentes e/ou indicadores explícitos; v) enquadramento legal do relatório; vi) construção e aprovação do documento; vii) vinculações a outros documentos. Nesse caso dos relatórios, também procedemos à contagem dos conceitos aí presentes na sua ligação à gramática gerencialista ou à democrática.

\section{A Lei da avaliação da educação e do ensino não superior}

A Lei n. ${ }^{\circ}$ 31/2002, de 20 de dezembro, aprovou o sistema de avaliação da educação e do ensino não superior em Portugal e apresentou como objetivos da avaliação os seguintes (art. $\stackrel{\circ}{3} . \stackrel{\circ}{)}$ ):

- promover a melhoria da qualidade do sistema educativo, da sua organização e dos seus níveis de eficiência e eficácia;

- dotar a administração educativa local, regional e nacional de um quadro de informações sobre o funcionamento do sistema educativo;

- assegurar o sucesso educativo promovendo uma cultura de qualidade, exigência e responsabilização;

- incentivar as ações e os processos damelhoria da qualidade, do funcionamento e dos resultados das escolas;

- garantir a credibilidade do desempenho dos estabelecimentos de educação e ensino;

- promover uma cultura de melhoria continuada da organização,do funcionamento e dos resultados do sistema educativo e de projetos educativos;

- participar nas instituições e nos processos internacionais de avaliação dos sistemas fornecendo informação e recolhendo experiências comparadas em termos internacionais de referência.

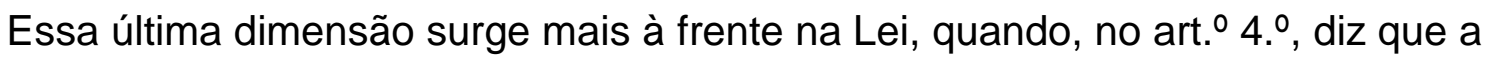
avaliação se desenvolve "numa concepção de avaliação que, a partir de uma análise de diagnóstico, vise a criação de termos de referência para maiores níveis de exigência" e que "o sistema de avaliação deve, através da participação 


\section{movimento \\ faculdade de educação - programa de pós-graduação em educação universidade federal fluminense \\ issn 2359-3296 \\ ano 5 número 8 - 2018}

em projectos e estudos desenvolvidos a nível internacional, permitir aferir os graus de desempenho do sistema educativo nacional em termos comparados".

Assim, por um lado, reforçam-se as funções de avaliação como instrumento para o desenvolvimento da qualidade associada à melhoraria dos níveis de exigência, mas, também, a sua importância na reunião de elementos que possam ser comparáveis com outros referenciais externos em sintonia com as demandas/regulações supranacionais.

A Lei aponta para a necessidade de processos de avaliação interna e externa. Contudo, infere-se que, apesar de ser dado enfase à avaliação interna como base do processo avaliativo, é necessário que ela seja devidamente verificada e certificada como válida pelas entidades externas (Inspeção da Educação), dando-se protagonismo à faceta da avaliação externa em detrimento da interna.

Parece claro que a avaliação externa se assume como protagonista no processo de avaliação das organizações educativas. Tendo em conta essa valorização legal, de certa forma, é natural que os seus referenciais tenham impacto nos processos de avaliação interna. Para ilustrar essa ideia, recordamos o que diz a Lei: "o processo de auto-avaliação deve conformar-se apadrões de qualidade devidamente certificados" $\left(\right.$ art. $\left.^{\circ} 7^{\circ}\right)$. O art. $^{\circ}$ 9..$^{\circ}$ aponta um conjunto de indicadores a ter em conta nos processos de avaliação:

a) Cumprimento da escolaridade obrigatória;b) Resultados escolares, em termos, designadamente, de taxa de sucesso, qualidade do mesmo e fluxos escolares; $c$ ) Inserção no mercado de trabalho; d) Organização e desenvolvimento curricular; e) Participação da comunidade educativa;f) Organização e métodos e técnicas de ensino e de aprendizagem, incluindo avaliação dos alunos e utilização de apoios educativos; g) Adopção e utilização de manuais escolares; h) Níveis de formação e experiência pedagógica e científica dos docentes; i) Existência, estado e utilização das instalações e equipamentos;j) Eficiência de organização e de gestão; I) Articulação com o sistema de formação profissional e profissionalizante;

m) Colaboração com as autarquias locais; n) Parcerias com entidades 


\section{movimento \\ faculdade de educação - programa de pós-graduação em educação universidade federal fluminense \\ issn 2359-3296 \\ ano 5 número 8 - 2018}

empresariais; o) Dimensão do estabelecimento de ensino e clima e ambiente educativos.

Esses indicadores acabam por ter um impacto significativo, quer nos pressupostos e nos conceitos utilizados nas produções discursivas dos atores (equipas de avaliação externa e equipas de avaliação interna), quer na forma como se estruturam os vários relatórios de avaliação.

Por fim, salientamos o fato de estar prevista a disponibilização da informação da avaliação das escolas, remetendo para processos de natureza comparada, como expresso no art.16:

Os resultados da avaliação das escolas e do sistema educativo, constantes de relatórios de análise integrada, contextualizada e comparada, devem ser divulgados com o objectivo de disponibilizar aos cidadãos em geral e às comunidades educativas em particular uma visão extensiva, actualizada, criticamente reflectiva e comparada internacionalmente do sistema educativo português.

Uma outra leitura que fizemos dessa Lei, a qual introduziu a avaliação das escolas em Portugal, foi proceder à identificação e à contagem de um conjunto de conceitos, uns que podem ser considerados como associados à gramática gestionária e outros à democrática. Contabilizamos quarenta e seis conceitos e/ou expressões referentes a uma visão gestionária da educação, entre os quais: resultados (dez vezes), qualidade (seis vezes), eficiência, eficácia, sucesso, padrões, taxas, exigência, responsabilização, credibilidade, indicadores, desempenho, comparar resultados, boas práticas, grau de execução, grau de concretização, nível de certificação.

Em relação ao número de conceitos associados à gramática democrática, assinalamos mais de dezoito: comunidade educativa (cinco vezes), contextualização de resultados (três vezes), desenvolvimento integral, 


\section{movimento \\ faculdade de educação - programa de pós-graduação em educação universidade federal fluminense \\ issn 2359-3296 \\ ano 5 número 8 - 2018}

participação da comunidade, valorização do clima, integração social, emoções, afetividade.

Nesta Lei $n$. ${ }^{31 / 2002}$, a avaliação surge como um instrumento de definição de políticas educativas, inferindo-se um efeito de forte regulação dos processos avaliativos, dada a lógica de imposição do centro para as periferias. Os objetivos remetem-nos para a valorização das funções de garantia da qualidade (associada à eficácia e à eficiência) e para a prestação de contas como forma de garantir a credibilidade, bem como para a sua importante função na recolha de informação que permita desenvolver estudos comparados internacionais. Trata-se portanto de um normativo que assume um forte caráter prescritivo, sendo ainda notória a sua dimensão técnico-reguladora de feição gestionária.

\section{Documentos orientadores da avaliação produzidos pela Inspeção}

Um outro documento que consideramos importante para o estudo é o Quadro de referência para a avaliação externa das escolas, haja vista o impacto que nos parece ter nas representações e nos discursos dos atores que desenvolvem os processos de avaliação interna. O documento constitui um guião de procedimentos, apresentando as diretrizes para esses agentes seguirem durante os processos de avaliação.

O Quadro de referência para a avaliação externa das escolas define os objetivos, os domínios, os campos de análise e referentes, a metodologia de intervenção da equipa de avaliação externa e os descritores dos níveis de classificação utilizados (escala de avaliação). Integra ainda as indicações para a construção do documento de apresentação da escola a fazer pela respetiva Direção, aquando da visita da equipa de avaliação externa. 


\section{movimento \\ faculdade de educação - programa de pós-graduação em educação universidade federal fluminense \\ issn 2359-3296 \\ ano 5 número 8 - 2018}

Relativamente às orientações gerais dos processos, podemos dizer que elas seguem de perto as indicações apresentadas na Lei nำ31/2002, reforçando as lógicas gestionárias, reguladoras e tecnocráticas da avaliação. Recordamos os objetivos expressos no documento:

(...) identificar pontos fortes e áreas prioritárias para a melhoria do trabalho das escolas; incrementara responsabilização a todos os níveis validando as práticas de autoavaliação das escolas; fomentar a participação na escola da comunidade educativa e da sociedade local, oferecendo um melhor conhecimento público da qualidade do trabalho das escolas; contribuir para a regulação dotando os responsáveis pelas políticas educativas e pela administração das escolas de informação pertinente.

Salientamos, ainda, que os domínios campos de análise e referentes encontramse em sintonia com o expresso na Lei $n .0$ 31/2002. A apresentação da metodologia de trabalho e da escala de avaliação, que a equipa de avaliação pretende utilizar, favorece o desenvolvimento de processos hegemónicos da avaliação externa sobre a interna, na medida em que é imposta uma agenda de trabalho e de discurso com caminhos e referenciais bem determinados.

As imposições apresentadas nos documentos relativamente aos processos a desenvolver no âmbito avaliativo, bem como a centralidade que a escala de avaliação assume nos documentos faz com que se percecionem regulações fortes das equipas de avaliação externa sobre as de avaliação interna e docentes em geral.

\section{Análise dos relatórios de avaliação externa das escolas}

Como já referido, foram recolhidos dez relatórios de avaliação externa de escolas produzidos pela Inspeção da Educação que analisamos de acordo com as categorias anteriormente expostas. Com um olhar panorâmico, podemos afirmar que a quantidade de termos indexados à gramática gerencialista é francamente 


\section{movimento \\ faculdade de educação - programa de pós-graduação em educação universidade federal fluminense \\ issn 2359-3296 \\ ano 5 número 8 - 2018}

superior ao de termos integrados à democrática em todos os relatórios analisados.

Da análise global de todos os relatórios, os conceitos mais utilizados foram: em primeiro lugar, o termo resultados (com uma média de 20 vezes por relatório); em segundo, melhoria (com uma média de 15 vezes por relatório); em terceiro, impacto (com uma média de 9 vezes por relatório). Aparecem muitos outros termos e expressões ao longo dos documentos em quantidade assinalável, os quais demonstram que estamos perante um discurso marcadamente gestionário, a saber: sucesso, indicadores, valores esperados, pontos fortes, eficazes, taxas, monitorização, qualidade, entre outros.

Em relação a termos ou a expressões consideradas integradas em uma gramática democrática, temos a expressão comunidade educativa (que surge 8 vezes em média por relatório); depois assinalamos o termo participação (com uma média de 6 vezes por relatório). São encontrados vários outros em baixa quantidade pertencentes a uma gramática democrática, a saber: envolvimento, colaboração, solidariedade, equidade e inclusão.

Todos os relatórios apresentam um conteúdo semelhante, com o mesmo tipo de discurso, debruçando-se sobre certos pontos que entendemos serem aspetoschave na "lente" utilizada pelas equipas de avaliação externa. Essa orientação é patente em todos os pontos. Em todos os relatórios, na Introdução é apresentada a lei enquadradora da avaliação das organizações educativas (Lei nํㅜ 31/2002, de 20 de dezembro, e outros normativos) e explica-se que essa ação é uma demanda externa do poder de tutela, o que deixa em evidência o reforço dos normativos legais que induz à atribuição de um poder legal a ser exercido sobre as organizações educativas. 


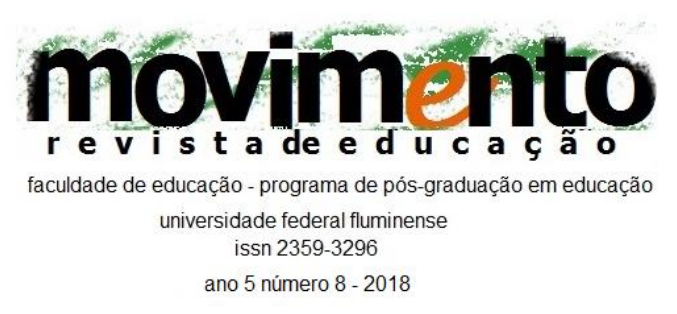

Posteriormente, são apresentadas as funções da avaliação externa, assumindose que se pretende contribuir para a consolidação dos processos de avaliação interna e uma oportunidade para a "melhoria para a escola" (aspeto que é mencionado na Lei oㅜ 31/2002, de 20 de dezembro). Assinalamos, portanto, a conformidade do discurso da Inspeção com o discurso político-legal veiculado nos normativos.

É destacada também a escala de avaliação utilizada pelos avaliadores. Esse reforço da dimensão mensurável do processo pode ser lido como a valorização da avaliação/classificação como instrumento de poder. Um outro aspeto presente nos relatórios é a comparação de uma escola relativamente a outras no que diz respeito às variáveis do contexto.

Saliente-se a homogeneização do discurso em todos os relatórios em relação à valorização de percentagens e de comparações. Especificamente no que se reporta aos resultados académicos, o discurso favorece quem recolhe de forma sistematizada informação da evolução das aprendizagens das crianças (depreendemos dados estatísticos dada a valorização manifestada nessa subdimensão). Os resultados da escola (provas finais das disciplinas que têm exames externos) são analisados tendo em conta a comparação com escolas com valores análogos nas variáveis de contexto. Há sempre uma preocupação na comparação com os resultados esperados. Em todos os relatórios, ressaltase a importância da reflexão com os resultados, fazendo referência à avaliação SWOT. Ainda são mencionados os dados (percentagens) de taxas de abandono e de desistência.

No que diz respeito à avaliação de resultados sociais, ela centra-se na quantificação e na enumeração de projetos e de parcerias com as famílias e as instituições, o que favorece o desenvolvimento integral das crianças e dos jovens. Em todos os relatórios, também há uma atenção à indisciplina e, por isso, 


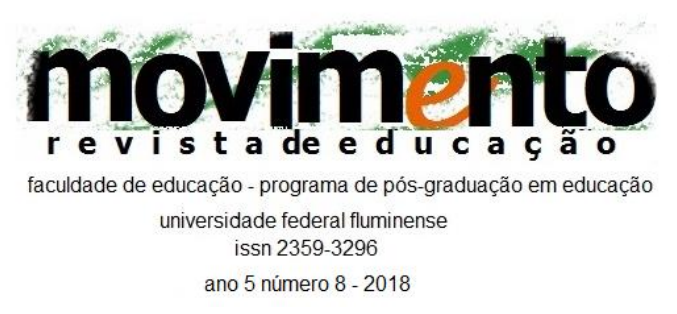

olha-se com especial atenção para o número de ocorrências de transgressões em ambiente educativo. São também enumeradas as iniciativas para correção da situação. Na maior parte dos relatórios, igualmente é referido se a escola desenvolve «boas práticas» e, explicitamente, quadros de valor e de excelência, concursos e atividades que favoreçam a atribuição de prémios.

É dada ainda uma especial atenção à gestão dos recursos, sendo avaliada pela lógica da rentabilização. No ponto monitorização e avaliação do ensino e das aprendizagens, há um olhar atento sobre os processos de avaliação dos alunos (instrumentos e processos) e da escola e outros mecanismos avaliativos como de projetos da organização. É valorizada a produção de instrumentos comuns de avaliação, a elaboração conjunta de matrizes e de provas de avaliação e a aferição e uniformização de critérios.

Em relação à liderança e à gestão, podemos constatar que há uma valorização da liderança unipessoal. Vemos frequentemente a expressão "o diretor e sua equipa", através da associação desse tipo de liderança à melhoria de processos organizacionais, à relação interinstitucional, às questões do clima organizacional e à identidade à cultura de trabalho. As lideranças intermédias são avaliadas em um papel de reconhecimento das diretrizes e dos desafios da escola (partindose da ideia de que é a direção que determina) e pelo seu "compromisso na sua execução".

No ponto da gestão, salientamos um aspeto de avaliação que é comum a praticamente todos os relatórios analisados. Trata-se da valorização da existência de uma "estratégia definida e generalizada de comunicação com 0 exterior e de projeção da imagem de escola". Em relação aos processos de autoavaliação, é valorizado o impacto positivo na melhoria dos processos (evidências comprováveis). São também destacados acompanhamentos externos às escolas (parcerias com instituições científicas ou técnicas que 


\section{movimento \\ faculdade de educação - programa de pós-graduação em educação universidade federal fluminense \\ issn 2359-3296 \\ ano 5 número 8 - 2018}

permitam a melhoria dos processos avaliativos). Por fim, em todos os relatórios, são apresentados os pontos fortes e as áreas de melhoria, com base nos valores esperados em cada domínio e tendo em conta os pontos fortes e fracos que em cada dimensão é atribuída uma classificação.

Em jeito de nota conclusiva sobre os relatórios de avaliação externa das escolas e tendo em conta as nossas categorias, podemos referir: i) estrutura -ela é a mesma em todos os relatórios observados e o número de páginas varia entre doze e catorze; ii) orientações gerais dos processos - é feita em todos os relatórios uma apresentação clara dos processos que vão ser desenvolvidos no relatório, registando-se uma homogeneização discursiva; iii) domínios e campos de análise - são exatamente os mesmos em todos os relatórios; iv) referentes e/ou indicadores explícitos - os pontos destacados para análise e avaliação são os mesmos em todos os relatórios, digamos que a "lente" de observação está focada em aspetos tidos e naturalizados como certos e positivos ou seja "boas práticas"; v) enquadramento legal do relatório - em todos os relatórios é visível a importância da legislação como forma de legitimação da ação avaliativa externa; vi) construção e aprovação do relatório - o documento tem a mesma estrutura e conteúdo semelhante em todos os relatórios e foi aprovado pela tutela central; vii) vinculações a outros documentos - em todos os relatórios é visível a vinculação expressa aos normativos legais definidos centralmente.

\section{Análise dos relatórios de avaliação interna das escolas}

Passamos agora a apresentar as conclusões da análise dos dez relatórios de avaliação interna recolhidos via internet. Tal como os relatórios de avaliação externa, também esses foram analisados segundo as categorias atrás expostas. Com um olhar panorâmico, podemos afirmar que a quantidade de conceitos 


\section{movimento \\ faculdade de educação - programa de pós-graduação em educação universidade federal fluminense \\ issn 2359-3296 \\ ano 5 número 8 - 2018}

indexados à gramática gerencialista é francamente superior ao número de termos integrados na democrática em todos os relatórios analisados.

Os conceitos mais utilizados foram: em primeiro lugar, o termo taxas (com uma média de 45 vezes por relatório); em segundo, resultados (com uma média de 34 vezes por relatório); em terceiro, sucesso (com uma média de 22 vezes por relatório). Aparecem outros termos e outras expressões em quantidade assinalável ao longo dos documentos, os quais denotam o discurso marcadamente gestionário, a saber: qualidade, indicadores, grau de concretização, pontos fortes, eficazes, metas, monitorização, melhoria, inovação, valores de referência, médias, desempenho, entre outros.

Em relação a conceitos ou a expressões consideradas integradas em uma gramática democrática, temos a expressão comunidade educativa (que surge em média 8 vezes por relatório) e depois o termo participação (com uma média de 6 vezes por relatório). São encontrados outros termos em baixa quantidade também pertencentes a essa gramática democrática, a saber: envolvimento, colaboração, equidade e inclusão.

Todos os relatórios apresentam uma estrutura e um conteúdo que seguem de perto a lógica de estruturação dos relatórios de avaliação externa produzidos pela Inspeção da Educação, à exceção da dimensão, já que alguns são muito extensos, chegando às 150 páginas. São muito descritivos e apresentados em uma lógica de diagnóstico da situação, sendo a sua principal caraterística a apresentação de dados (médias, percentagens, taxas), especialmente referentes à avaliação dos resultados dos alunos. Em contrapartida, a análise administrativo-organizativa é feita de forma sumária. Todos integram uma componente reservada à análise de pontos fortes e fracos, bem como a planos ou a recomendações para a melhoria. 


\section{movimento \\ faculdade de educação - programa de pós-graduação em educação universidade federal fluminense \\ issn 2359-3296 \\ ano 5 número 8 - 2018}

Encontra-se também expressa a metodologia utilizada no processo de avaliação. Nota-se uma preocupação em mostrar que os processos obedecem ao rigor que se espera para que possam ser validados pela Inspeção. Assim, em 3 dos 10 relatórios, opta-se pela metodologia CAF (Common Assessment Framework), a qual se baseia em uma estrutura de autoavaliação concetualmente semelhante aos principais modelos de Gestão da Qualidade Total (TQM), particularmente ao Modelo de Excelência da EFQM (European Foundation forQuality Management).

Regista-se uma preocupação, visível em todos os relatórios, com demonstrar aquilo que thes é solicitado, manifesta na quantificação de dados e na comparação com valores de referência. Em média, a utilização de gráficos e de tabelas ocupa cerca de $75 \%$ das páginas de todo o relatório. Em relação às funções da avaliação, vários relatórios demonstram que se trata de um processo importante para a melhoria da escola, portanto, em consonância com o discurso presente no normativo enquadrador do processo e também no discurso veiculado pelas equipas da Inspeção.

Em vários outros relatórios, é possível encontrar objetivos que revelam preocupação em perceber o grau de execução, o nível de desempenho e as taxas de sucesso. Não se encontra em nenhum desses estudados uma análise crítica e aprofundada dos resultados dos alunos. Há uma preocupação em responder às questões nucleares expressas nos documentos legais e nos relatórios de avaliação externa, em particular, aquelas que se referem às taxas de sucesso e às comparações com os valores esperados. A questão dos resultados nas provas e nos exames externos é uma constante. Outros aspetos são a questão da taxa de desistência, os registos de episódios de indisciplina, o número de projetos e atividades e os apoios para os alunos. Em muitos relatórios, é atribuído valor a algumas "boas práticas" (também identificadas pelas equipas de avaliação externa) como a existência de concursos, quadros de valor e excelência e mérito. 


\section{movimento \\ faculdade de educação - programa de pós-graduação em educação universidade federal fluminense \\ issn 2359-3296 \\ ano 5 número 8 - 2018}

As questões associadas e referenciadas nos documentos da Inspeção, como é o caso do desempenho das lideranças, do trabalho de articulação entre docentes e das parcerias realizadas, são aspetos que surgem explorados em todos os relatórios, sendo que há dois fatos que aparecem com grande centralidade em todos os relatórios: os dados relativos aos resultados académicos e à enumeração dos aspetos fortes e aqueles que precisam melhorar.

Nos relatórios analisados, os discursos são muito homogéneos, pois a tendência global é a assunção de uma proposta de natureza tecnocrática e operacional (baseada no "mito" do rigor), profundamente marcada pela lógica gestionária. Em relação aos resultados académicos, os relatórios procuram expressar que foi feita uma recolha de dados estatísticos de forma sistematizada (por exemplo, em relação à evolução das aprendizagens dos alunos).

Tal como é feito pela equipa de avaliação externa, também os resultados dos alunos das escolas são comparados e analisados tendo em conta a comparação com escolas com contextos análogos. Em todos os relatórios, é verificada a importância da reflexão dos resultados, fazendo referência à avaliação SWOT. Assim como é feito nos relatórios de avaliação externa, a avaliação de resultados sociais centra-se na quantificação e enumeração de projetos e parcerias com as famílias e as outras instituições e na quantificação das ocorrências e medidas corretivas, sancionatórias e preventivas que estão em curso para tratar a indisciplina.

Em jeito conclusivo sobre os relatórios de avaliação interna das escolas e tendo em conta as nossas categorias, podemos referir: i) estrutura - é diferente em todos os relatórios, embora possamos indicar que, nos três em que foi utilizada a metodologia $C A F$, as estruturas sejam próximas; são documentos muito extensos com uma média de 60 páginas; integram muitos gráficos e quadros de 


\section{movimento \\ faculdade de educação - programa de pós-graduação em educação universidade federal fluminense \\ issn 2359-3296 \\ ano 5 número 8 - 2018}

dados; ii) orientações gerais dos processos - é feita em todos os relatórios uma apresentação dos processos que vão ser desenvolvidos no relatório, com destaque para a metodologia, para as fases do processo avaliativo, para os domínios de análise e indicadores ou descritores e para as estratégias de ação para a melhoria com base no levantamento de pontos fracos e constrangimentos; iii) domínios e campos de análise - estão muito próximos daqueles que estão presentes nos relatórios de avaliação externa desenvolvidos pelas equipas da Inspeção (em alguns casos são exatamente os mesmos); iv) referentes e/ou indicadores explícitos - os pontos destacados para análise e avaliação são os mesmos em todos os relatórios, digamos que a "lente" de observação está focada em aspetos tidos e naturalizados como certos e positivos ou seja "boas práticas"; também aqui é a medição e a comparação que imperam em todos os relatórios; v) enquadramento legal do relatório - em quase todos os relatórios se invoca a legislação e é apresentada, tal como nos relatórios de avaliação externa, como uma resposta às demandas legais; vi) construção e aprovação do documento - é feita referência aos participantes, sendo, na maioria dos casos, equipas que integram vários elementos da comunidade educativa, incluindo muitas vezes alunos e encarregados de educação; alguns relatórios (cerca de metade) indicam a aprovação nos órgãos de gestão da escola; vii) vinculações a outros documentos - em todos os relatórios é visível a vinculação aos normativos legais e, em alguns, é feita referência aos relatórios de avaliação externa.

\section{Considerações finais}

Os processos de avaliação das escolas que têm sido desenvolvidos e valorizados em Portugal assumem conceções e procedimentos que se aproximam tendencialmente das lógicas gerencialista e mercantil. Orientados na sua conceção para responder à função de comparabilidade e de controlo, esses 


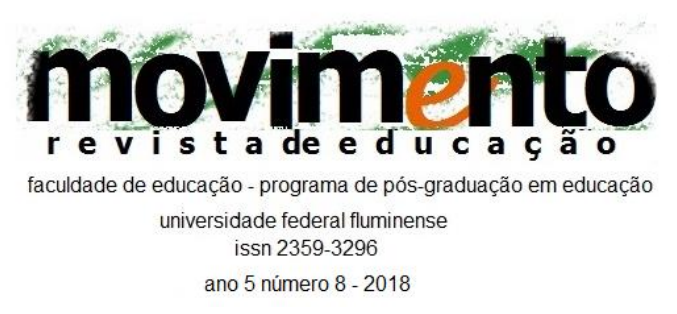

processos, implementados nas organizações educativas, veem reforçada a sua faceta quantitativa de modo a permitir comparar instituições e profissionais. Os discursos desenvolvidos pelos atores nas organizações educativas, no registo oral ou no escrito, seguem de perto aqueles que são veiculados nos relatórios de avaliação externa das escolas (da responsabilidade da Inspeção da Educação) e os que são difundidos nos normativos legais.

Assim, entendemos que os próprios atores acabam por facilitar ou mesmo intensificar uma certa subordinação a centros instituídos e, ao mesmo tempo, alimentam as lógicas de mercado educacional que se afirma. Por sua vez, as equipas de avaliação externa reproduzem e executam um trabalho subordinado ao poder central. Nesse sentido, os referenciais que suportam essa realidade são criados de cima para baixo por entidades externas às organizações educativas e que ditam as regras do jogo avaliativo, impondo de forma muitas vezes oculta - ou menos explicita - os caminhos que deverão ser seguidos, no próprio processo avaliativo ou nas metas a atingir.

As lentes para analisar a realidade são desenvolvidas com base no que deverá ser observado e testado e os atores nos diferentes contextos vão-se guiando por essas mesmas lentes através daquilo que alguns autores referem como contaminação (CORREIA, 1999). A fraca participação desses atores (profissionais de educação) nesses processos levou a que fosse mais fácil a imposição de modelos às escolas e aos profissionais, restrigindo estes, normalmente, a cumprir ou a executar o que foi previamente definido e que é aplicado em uma lógica top-down.

Segundo Machado e Grilo (2009), a "natureza externa do processo explica em grande parte a atitude hostil dos professores perante o processo". Como referem Formosinho e Machado (2007), e referenciados por Machado e Grilo (2009), esses processos constituem "uma realidade que existe para lá da acção dos 


\section{movimento \\ faculdade de educação - programa de pós-graduação em educação universidade federal fluminense \\ issn 2359-3296 \\ ano 5 número 8 - 2018}

professores", uma forma oficial de fazer as coisas que "estrutura e condiciona o pensamento e a acção de quem trabalha na escola" (FORMOSINHO \&MACHADO, 2007, p. 101). Os autores entendem ainda que a dimensão externa dos processos de avaliação tem um grande impacto nos processos de avaliação interna, subordinando-se a dimensão interna à externa por adaptação. As regulações exercidas pelos processos de avaliação externa na vida das organizações e dos profissionais condicionam fortemente a direção do trabalho pedagógico.

Nesses últimos tempos, os rankings das escolas assumiram algum destaque na comunicação social, ajudando a legitimar determinadas decisões no campo educacional, nomeadamente, o desenvolvimento do discurso da livre escolha de escola, a criação dos contratos de associação de escolas (parcerias públicoprivadas), a reorganização da rede de escolas públicas com argumentos de racionalização de recursos, com incidência em determinadas zonas do país, especialmente nas periféricas.

\section{Referências}

AFONSO, A. Políticas educativas e avaliação das escolas: por uma prática avaliativa menos regulatória. In J.COSTA, A.NETO-MENDES \& A.VENTURA. Avaliação de Organizações Educativas. Aveiro: Universidade de Aveiro, 2002, pp.31-37.

AFONSO, A. Políticas educativas e auto-avaliação da escola pública portuguesa: apontamentos de uma experiência. Estudos Avaliação Educacional. São Paulo, 2010, vol. 21, n. 46, pp.343-362.

AFONSO, N. Avaliação e desenvolvimento organizacional da escola. In J. COSTA, A. NETO-MENDES \& A. VENTURA.Avaliação de Organizações Educativas. Aveiro: Universidade de Aveiro, 2002, pp.51-68. 


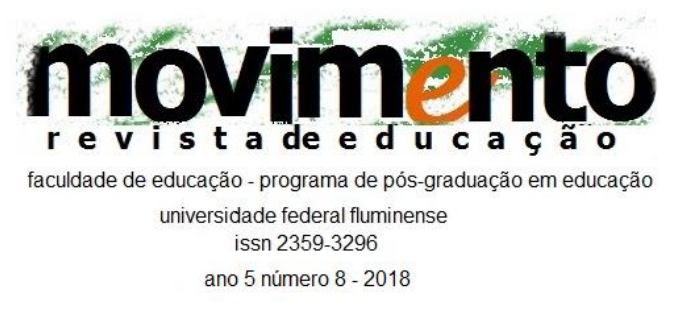

AFONSO, N. A Direcção Regional de Educação: um espaço de regulação intermédia. In J.BARROSO (org.). A Regulação das políticas públicas da educação: espaços, dinâmicas e actores.Lisboa: Educa, 2006, pp. 71-96.

AZEVEDO, J. (coord.). Avaliação das Escolas. Consensos e Divergências. Porto: Asa, 2002.

AZEVEDO, J.A educação de todos e ao longo de toda a vida e a regulação sociocomunitária da educação. Comunicação ao $2^{\circ}$ Encontro de Pedagogia social. Porto: Universidade Católica Portuguesa, 2008 (documento não publicado).

BARROSO, J.\& VISEU, S. A emergência de um mercado educativo no planeamento da rede escolar: de uma regulação pela oferta a uma regulação pela procura. Educação, Sociedade, Campinas,2003, vol. 24, n.. 84, pp. 897921.

BARROSO, J. Políticas Educativas e Organização Escolar. Lisboa: Universidade Aberta, 2005.

BARROSO, J. A Regulação das Políticas Públicas de Educação: Espaços, dinâmicas actores.Lisboa:Educa, 2006.

CASTRO, D. Os Projetos de Intervenção dos Diretores de Escola: uma construção discursiva a partir das regulações do discurso político-normativo. SENSOS, Porto, 2011, vol. I, pp.9-28.

CASTRO, D. (2015). O desenvolvimento do sistema educativo estatal em Portugal: um percurso marcado por regulações externas e pela centralização de poderes. In D. SOUZA, M. DUARTE \& R. OLIVEIRA (orgs.) Sistemas Educacionais: concepções, tensões e desafios. S. Paulo: Edições LOYOLA, 2015, pp. 49-65.

CASTRO, D., FIGUEIREDO, I. \& DIOGO, F. A regulação do poder central no processo de construção das Cartas Educativas e a homogeneização dos discursos. In Atas do II Colóquio Internacional de Ciências Sociais de Educação "O Governo das Escolas, Atores, Políticas e Práticas". Braga: Universidade do Minho, 2015, pp. 1278-1285.

CASTRO, D. Reconfiguração do discurso político-normativo: da lógica democrática à lógica gerencialista. EXITUS, 2016, vol. 6, n.ำ 2, pp. 180-193.

CASTRO, D. A Avaliação das Organizações Educativas como instrumento indutor de lógicas de mercado educacional. In N. FERREIRA, M. FONTANA 


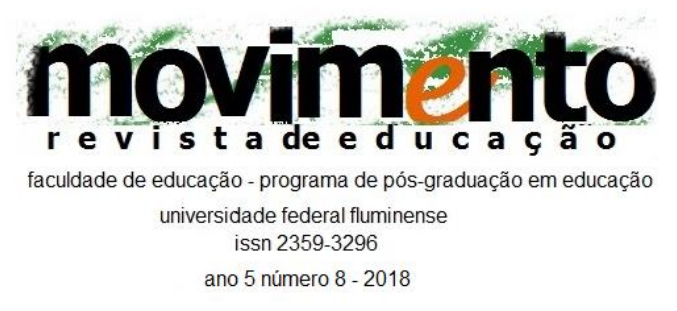

\&J. SALOMÉ. Políticas Públicas e gestão democrática: desafios e compromissos. Curitiba: Editora CRV, 2017, pp.41-63.

COSTA, J.Projectos em Educação. Contributos de análise organizacional. Aveiro: Universidade de Aveiro, 2007.

CORREIA, J. As ideologias educativas em Portugal nos últimos 25 anos. Revista Portuguesa de Educação, Braga, 1999, vol. 12, n.․ 1, pp. 81-110.

DIAS, M.As políticas "locais" de educação e a profissão de professor: novos contextos de trabalho, novas identidades profissionais. In J. COSTA, A. NETOMENDES \& A. VENTURA (org.). Políticas e gestão local da educação: Aveiro: Universidade de Aveiro, 2004, pp. 225-265.

ESTÊVÃO, C. Educação, conflito e convivência democrática. Ensaio: Avaliação e Políticas Públicas em Educação,Rio de Janeiro, 2008, vol. 16, out.-dez, pp. 503-512.

FORMOSINHO, J. \& MACHADO, J. A Modernidade, Burocracia e Pedagogia. In J. SOUSA \& C. FINO (Org.). A Escola Sob Suspeita. Porto: ASA,2007, pp. 97-119.

FONTOURA, M. Política e acção pública: entre uma regulação centralizada e uma regulação multipolar. Revista Portuguesa de Educação, Braga, 2008, v.

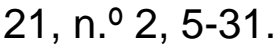

GAZİEL, H., WARNET M. \& CANTÓN MAYO, I.La Calidad en los Centros Docentes del Siglo XXI: Propuestas y Experiencias Prácticas. Madrid: La Muralla, 2000.

LIMA, L. Modernização, racionalização e optimização: perspectivas neotaylorianas na organização e administração da educação. Cadernos de Ciências Sociais, 1994, n.ำ 14, pp. 119-139.

LIMA, L. Avaliação e concepções organizacionais de escola: para uma hermenêutica organizacional. In J. COSTA. A. NETO-MENDES\&A. VENTURA. Avaliação de Organizações Educativas. Aveiro: Universidade de Aveiro, 2002, pp.17-29.

LIMA, L. Concepções de escola: para uma hermenêutica organizacional. In L. LIMA (org.) Compreender a Escola. Perspectivas de análise organizacional.

Porto: ASA, 2006, pp. 17-69. 


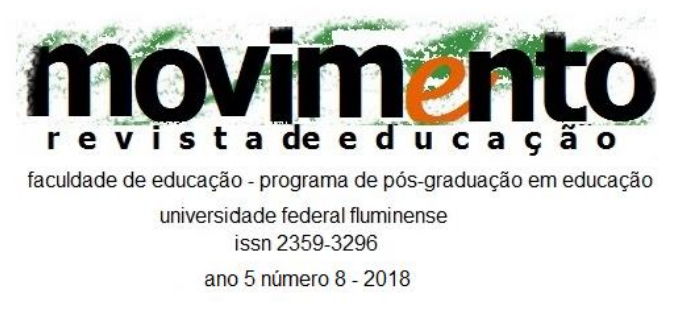

LIMA, L. Concepções de Escola: para uma hermenêutica organizacional. In L. LIMA et al. (Org.). Perspectivas de Análise Organizacional das Escolas. Vila Nova de Gaia: Fundação Manuel Leão, 2011, pp.15-57.

MACHADO, J. \&GRILO, V. Avaliação das escolas e actores locais: responder ou melhorar? Actas $X$ Congresso Internacional Galego-Português de Psicopedagogia, Braga: Universidade do Minho, 2009, pp.3545-3559.

MOREIRA, M. Avaliação institucional escolar: um estudo exploratório de uma experiência. Dissertação de Mestrado. Braga, Universidade do Minho, 2005.

NETO-MENDES, A. Regulação estatal, auto-regulação e regulação de mercado: subsídios para o estudo da profissão docente. In J.COSTA, A. NETOMENDES \& A.VENTURA (org.). Políticas e Gestão Local da Educação. Aveiro: Universidade de Aveiro, 2004, pp. 23-33.

NÓVOA, A. Modelos de Análise de Educação comparada: o campo e o mapa. In D. SOUZA \&S. MARTíNEZ (org.). Educação Comparada. Rotas de AlémMar. São Paulo: Xamã, 2009, pp.22-62.

PACHECO, J. Discursos e lugares das competências em contextos de educação e formação. Porto: Porto Editora, 2011.

PINHAL, J. A intervenção do município na regulação local da educação. In J. BARROSO (org.) A regulação das políticas públicas de educação: espaços, dinâmicas e actores. Lisboa: Educa, 2006, pp. 99-128.

RUFINO, C. Avaliação interna das escolas e circulação de políticas públicas num espaço educacional europeu. Sísifo, Revista Ciências da Educação, 2007, n. $\stackrel{0}{4}$, pp. $29-38$.

SÁ, V. (2002). As políticas de escolha da escola pelos pais: da bondade das intenções à desilusão das realizações, ou talvez não! In J. COSTA, A. NETOMENDES \& A. VENTURA. Avaliação de Organizações Educativas. Aveiro: Universidade de Aveiro, 2002, pp. 69-92.

SEIXAS, A. Políticas educativas para o ensino superior: A globalização neoliberal e a emergência de novas formas de regulação estatal.In S. STOER, L. CORTEZÃO \& J. CORREIA (org.). Transnacionalização da Educação. Da crise da educação à "educação" da crise. Porto: Afrontamento,2001, pp. 209238.

SIMÕES, G. A auto-avaliação das escolas e a regulação da acção pública em educação. Sísifo, Revista Ciências da Educação, 2007, no 4, pp. 39-48. 


\section{movimento \\ faculdade de educação - programa de pós-graduação em educação universidade federal fluminense \\ issn 2359-3296 \\ ano 5 número 8 - 2018}

TEODORO, A. Organizações internacionais e políticas educativas nacionais: A emergência de novas formas de regulação transnacional, ou uma globalização de baixa intensidade. In S. STOER, L. CORTEZÃO \& J. CORREIA (org.). Transnacionalização da Educação. Da crise da educação à "educação" da crise. Porto: Afrontamento,2001, pp. 125-161.

\section{SOBRE OS AUTORES}

DORA FONSECA é doutora em Ciências da Educação. Professora do Departamento de Educação e Psicologia da Universidade de Aveiro, Portugal.

E-mail: dorafonseca@ua.pt

JORGE ADELINO COSTA é doutor em Ciências da Educação. Professor Catedrático do Departamento de Educação e Psicologia da Universidade de Aveiro, Portugal.

E-mail: jcosta@ua.pt

Recebido em: 02.04.2018

Aceito em: 28.05.2018 